\title{
EXCLUSÃO E RAÇA: INCURSÕES A PARTIR DO “RACISMO DE ESTADO” DE MICHEL FOUCAULT SOBRE O PROBLEMA DAS EXPERIÊNCIAS DAS DESIGUALDADES
}

\author{
José Mauro Garboza Júnior ${ }^{1}$ \\ Fernando Cesar Mendes Barbosa ${ }^{2}$
}

\begin{abstract}
Resumo
O presente trabalho discute como a exclusão social pode se dar por meio da exploração e reprodução no campo das raças. Procura-se entender as condições dentro das quais essa categoria bélico-política opera. No primeiro momento, são analisadas as noções de "racismo de estado" e "biopoder". Em seguida, são apresentadas algumas considerações que tocam às construções de formas sociais, dando ênfase no Direito como categoria ativadora de todo o "racismo de estado". Ao final, apresenta-se a situação atual em que vivemos, a partir da necessária mudança das configurações em defesa de um ambiente menos inóspito para toda a espécie humana.
\end{abstract}

Palavras-chave: Exclusão Social; Racismo de Estado; Biopoder; Raça; Desigualdades

\section{EXCLUSION AND RACE: ON "STATE RACISM" AND THE PROBLEM OF EXPERIENCES OF INEQUALITIES FROM FOUCAULT'S PERSPECTIVE}

\begin{abstract}
This paper aims to discuss how social exclusion occurs by means of exploration and reproduction in the field of races. We look to understand the conditions under which this political category acts. In the first part, we analyze the notions of "state racism" and "biopower". We present some considerations on the constructions of social forms, in order to emphasize Law as an activating category of all "state racism". At the end, we present the nowadays situation and the need of changing in defense of a less inhospitable environment for humankind.
\end{abstract}

Keywords: Social exclusion; State racism; Biopower; Race; Inequalities

\section{INTRODUÇÃO}

\footnotetext{
${ }^{1}$ Doutorando e Mestre em Ciência Jurídica pelo Programa de Pós-Graduação em Ciência Jurídica da Universidade Estadual do Norte do Paraná (PPGCJ-UENP), doutorando bolsista da Coordenação de Aperfeiçoamento de Pessoal de Nível Superior (CAPES) em Filosofia pelo Programa de Pós-Graduação em Filosofia da Universidade Estadual de Londrina (PPGFil-UEL). E-mail: garbozajm@gmail.com

${ }^{2}$ Advogado. Mestre em Ciência Jurídica pela Universidade Estadual do Norte do Paraná - UENP. É servidor da Universidade Federal da Integração Latino-Americana. Pesquisador do Grupo de Pesquisa BIOTEC - Direito, Biotecnologia e Sociedade, da Universidade Federal do Paraná. Doutorando em Direito no Programa de PósGraduação em Direito da Universidade Federal do Paraná - PPGD/UFPR. E-mail: fernandocesarmb@ gmail.com.
} 
A abordagem mais contemporânea das noções de garantias de direitos e de sua consequente defesa exigem que certos espaços de legitimação se deem por uma chave de leitura capaz de identificar o problema do racismo e da exclusão com vistas a sua superação. Nesse sentido, o presente trabalho tenta mostrar, a partir de algumas considerações do filósofo francês Michel Foucault, como a exclusão social pode se dar por meio da exploração e reprodução no campo das raças. Para tanto, será necessário entender as condições dentro das quais essa categoria bélico-política opera.

A "diferença de raças" deve ser entendida por meio de claras referências políticosociais, bem como a ênfase dada aos dispositivos jurídico-normativos a respeito de sua conceitualização. Trata-se de uma curiosa apropriação de uma referência que, em sua origem, pouco tem a ver com o campo da política (entendia-se a questão racial dentro do campo da biologia e mais precisamente do campo da naturalística). Esta transposição fundamental das raças é um dos motores das exclusões sociais no sentido mais amplo do termo - pode-se dizer, com a licença de se afirmar categoricamente, que toda formação social tem por base de sua montagem principal a exclusão de um, alguns ou muitos grupos. E que isso é mobilizado por meio da "política de raças".

Para que esta tese faça sentido, é preciso defender a correção de alguns termos nesse debate. O próprio conceito de raça deve ser entendido de forma pouco usual, pois, normalmente, quando se trata de raça, algumas das diferenças são notadas expressivamente ou pelas vias fenotípicas ou pelas vias culturais, mas sempre de um ponto de vista etnocêntrico no qual aquele que é indicado como outro é "menor" que o declarante. O objetivo é de apresentar o conceito de raça como núcleo de uma política pública estatal de longa data, que promove, ao fim e ao cabo, a mais incessante exclusão social. Longe de ser algo moderno ou atual, a política das raças está misturada com as agremiações sociais reprodutoras do que Foucault chamou de "racismo de estado".

A partir de uma metodologia eminentemente descritiva, por meio das referências bibliográficas acerca do tema, a estrutura escolhida está dividida em três partes, sendo que as duas primeiras são correlatas, e a terceira está em contraposição. Para o primeiro momento, trata-se de uma abordagem teórica cujo ensaio procura demonstrar as especificações terminológicas de uma filosofia ou teoria geral do tema do racismo; enquanto que no segundo momento, trata-se de observar como tais especificações se reproduzem na vida coletiva a partir da experiência daqueles que são vistos como excluídos. 
No primeiro momento, serão apresentadas algumas referências de Michel Foucault a respeito do que ele denominou "racismo de estado" e "biopoder" ao longo de sua trajetória intelectual. O que interessa está na forma como os problemas apareceram ao teórico e como, na medida de suas extensões de possibilidade de resolução, ele deu respostas à altura. Para um autor que sempre teve como preocupação processos de exclusão genéricos e de cujas linhas de pensamento seriam indissociáveis deles, Foucault desloca seu conjunto de preocupações em sutilezas terminológicas dignas de serem marcadas.

No segundo momento, serão apresentadas algumas considerações que tocam às construções de formas sociais derivadas das lições foucaultianas. Para tanto, quer-se apenas sublinhar que essa ideia originada de "racismo de estado" atualmente foi seguida a cabo por dois representantes, quais sejam, Achille Mbembe e Giorgio Agamben. Imaginando esses processos cada qual a seu modo, pode-se dizer que do "racismo de estado" derivou-se para este os conceitos tanto de "vida nua" e "estado de exceção", e para aquele tanto o conceito de "necropolítica" quanto de "devir-negro".

E por fim, um breve comentário sobre a situação atual em que vivemos com um simples medido de mudança das configurações em defesa de um ambiente menos inóspito para toda a espécie humana, o que se pretende fazer, no terceiro momento deste ensaio, para apresentar algumas considerações um pouco mais voltadas à realidade fática, em contraponto ao apresentado nas duas seções anteriores, mas, em certa medida na mesma direção, também para compreender outras formas de operabilidade, de construção e de estruturação do racismo na sociedade, tentando entender modelos de construção erigidos a partir de noções de raça e de racismo como estrutura social.

Por mais que o cunho sociológico ou filosófico pareça apagar o debate jurídico, é de suma importância perceber que o presente trabalho procura colocar em discussão, de modo não exaustivo, apenas a contraposição entre a teoria terminológica dos usos e abusos promovidos pelo "racismo de estado" cujo papel o próprio direito assume preponderantemente. As relações invisíveis e indeléveis não podem mascarar uma situação concreta e material de situações de exclusão que, na maioria dos casos, parecem passar ao largo dos compromissos jurídicos decisivos.

\section{FONTES DO PROBLEMA}


As formas sociais (jurídicas e políticas) automaticamente desembocam na fonte da exclusão. Durante quase trinta anos, o filósofo francês Michel Foucault se dedicou incansavelmente a essa problemática, e boa parte de sua vida foi dedicada ao entendimento desses processos, longos ou curtos, de índices que confirmam uma intuição de uma tese primordial: a tese de que não há sociedade sem a produção de um resto social, ou melhor, que toda sociedade já é o resultado de uma decisão sobre a produção política que produz seu resto.

Diversas foram suas fases, escritos e preocupações. Há já o cânone das três fases foucaultianas que, respectivamente, dizem respeito ao Saber, ao Poder e ao Sujeito. Há também comentários sobre as influências tanto da fenomenologia de Edmund Husserl quanto do modelo estruturalista em voga na França da década de 60. Suas polêmicas contra Jean-Paul Sartre a respeito da questão do humanismo e do anti-humanismo, do debate tensão com Jacques Derrida sobre a disputa de leituras envolvendo a segunda meditação do pensamento das Meditações Metafísicas de René Descartes, além do famoso encontro com Noam Chomsky a respeito da temática da natureza humana e o homem. Por esse ponto de vista, Foucault parece como que um pesquisador camaleônico se ajusta seu toma de acordo com os interesses e a conveniência, mas, assim como o animal camaleão, sempre se mantém preocupado com sua preocupação de fundo que é a questão da produção da exclusão social.

Para fins deste trabalho, quer-se apresentar três momentos da produção de sua obra que versam explicitamente sobre as questões que se desembocaram naquilo que poderia ser chamado a partir dos anos de 75-76 de "racismo de estado".

No primeiro momento, caso se utilize da cronologia linear de sua produção, um dos primeiros livros publicados pelo autor, o Doença mental e psicologia, já em seu último capítulo, ensaia algumas perspectivas sobre o mal-estar social diante da disjunção de satisfações do indivíduo e dos imperativos sociais (FOUCAULT, 2000, p. 71-98). Muito embora haja contribuições, como por exemplo a leitura assídua de Sigmund Freud e Friedrich Nietzsche com notas existencialistas bem particulares de uma França da década de 50, não há qualquer menção ao racismo de estado. Essa é uma forma recorrente em seus trabalhos.

A primeira aparição de temática localiza-se por volta de 1975 com a publicação de Vigiar a Punir. Segundo a perspectiva dos editores de seus seminários, é possível entender que o manuscrito foi escrito em sua primeira versão nos idos finais de 73, ano em que Foucault trabalhara com seus seminários nomeados de A Sociedade Punitiva (FOUCAULT, 2015, p. 258-259). Há ali algumas referências sobre o biopoder, uma forma de controle conjugada pelo 
poder soberano e o poder disciplinar que tem como foco último tanto o corpo quanto a cidade, uma forma de organização e ordenação do mundo que será a administração completa:

Para a articulação O corpo também está diretamente mergulhado num campo político, as relações de poder têm alcance imediato sobre ele; elas o investem, o marcam, o dirigem, o supliciam, sujeitam-no a trabalhos, obrigam-no a cerimônias, exigem-lhe sinais. Este investimento político do corpo está ligado, segundo relações complexa e recíprocas, à sua utilização econômica: é numa boa proporção como força de produção, que o corpo é investido por relações de poder e de dominação (FOUCAULT, 2014, p. 25).

As relações de poder configuram-se de tal forma que os comandos disciplinares anteriores a essa fase nem sequer alcançam o grau de dominação e sujeição do biopoder. Há de se destacar que Foucault entende esse fenômeno como algo eminentemente moderno. A sociedade disciplinar se preocupa com a administração das ações em busca de padroniza-las para antecipá-las. Como consequência direta, aqueles que não se adequam ou não se normalizam, não estão preparados tanto para serem reconhecidos pela sociedade como produtivos, quanto para terem um lugar específico nela. A exclusão é também um efeito colateral das técnicas disciplinares de todas as sociedades.

Por mais que o foco ainda seja em Vigiar e Punir o paradigma da disciplina e da norma, antecipando o modelo apresentado do biopoder, é possível perceber que os processos de exclusão se confundem com a identificação de um grupo não ajustável e sua imediata separação. Ainda que esse grupo não tenha contornos raciais muito claros, ou seja, eles não são excluídos porque são de tal grupos, mas apenas pelo seu não ajuste, coincidentemente ou não o conjunto de tais grupos excluídos e suas identificações convergem para uma aproximação (FOUCAULT, 2014, p. 192-193).

O segundo momento, que se segue desse momento da segunda metade da década de 70, a publicação do primeiro volume da história da sexualidade, A Vontade de Saber, em 1976, traz algumas novidades no que tange à perspectiva do biopoder e do racismo. Na parte final do livro, Foucault busca apresentar algumas outras perspectivas não contidas nos livros anteriores. Para tanto, ele inicia o debate do biopoder e do racismo a partir do papel que o próprio direito cumpre na promoção das desigualdades:

O conjunto perversão-hereditariedade-degenerescência constituiu o núcleo sólido das novas tecnologias do sexo. E não se imagine que se tratava apenas, de uma teoria médica cientificamente insuficiente e abusivamente moralizadora. Sua superfície de dispersão foi ampla e profunda a sua implantação. A psiquiatria, mais a jurisprudência, a medicina legal, as instâncias do controle social, a vigilância das crianças perigosas, ou em 
perigo, funcionaram durante muito tempo "pela degenerescência", pelo sistema hereditariedade-perversão. Toda uma prática social, cuja forma ao mesmo tempo exagerada e coerente foi o racismo de Estado, deu a essa tecnologia do sexo um poder temível e longínquos efeitos (FOUCAULT, 2017, p. 111).

A psiquiatria e a jurisprudência, unidas pela medicina lega, ou desunidas em seus campos próprios de controle social, garantem a vigilância de porções da população. Tais porções, por um longo processo de identificação e por outras razões que virão a seguir dá a ideia de que algo próprio desse grupo diz respeito à raça. É desse encontro com a medicina e com o direito que torna possível a aplicação de medidas estatais e governamentais o que Foucault chama de "racismo de estado". Não se trata de afirmar do nascimento do racismo no pensamento europeu. O que está em jogo é justamente a produção de uma forma específica de racismo que é produto do encontro dos saberes médicos e legais cuja finalidade será verificada nas práticas estatais de funcionamento. Para Foucault:

É aí, creio eu, que intervém o racismo. Não quero de modo algum dizer que o racismo foi inventado nessa época. Ele existia há muito tempo. Mas eu acho que funcionava de outro modo. O que inseriu o racismo nos mecanismos do Estado foi mesmo a emergência desse biopoder. Foi nesse momento que o racismo se inseriu como mecanismo fundamental do poder, tal como se exerce nos Estados modernos, e que faz com que quase não haja funcionamento moderno do Estado que, em certo momento, em certo limite e em certas condições, não passe pelo racismo (FOUCAULT, 2010, p. 304).

É, portanto, nesse terceiro momento em que a definição e conceituação do "racismo de estado" ganha sua proeminência. Na aula de 17 de março de 1976, Foucault toma algumas páginas para tratar especificamente dessa forma de racismo, esta agora definida e incorporada em seu léxico. É possível destacar que o racismo de estado está ligado de uma forma específica a toda e qualquer forma de totalitarismo (das sociedades oficialmente totalitárias às mais aparentemente democráticas). A forma de organização social cujo parâmetro fundamental é o governo das populações e a planificação dos viventes.

Com efeito, que é o racismo? É, primeiro, o meio de introduzir afinal, nesse domínio da vida de que o poder se incumbiu, um corte: o corte entre o que deve viver e o que deve morrer. No contínuo biológico da espécie humana, o aparecimento das raças, a distinção das raças, a hierarquia das raças, a qualificação de certas raças como boas e de outras, ao contrário, como inferiores, tudo isso vai ser uma maneira de fragmentar esse campo do biológico de que o poder se incumbiu; uma maneira de defasar, no interior da população, uns grupos em relação aos outros. Em resumo, de estabelecer uma cesura que será do tipo biológico no interior de um domínio considerado sendo precisamente um domínio biológico. (...) De outro lado, o racismo terá sua segunda função: terá como papel permitir uma relação positiva, se vocês 
quiserem, do tipo: 'quanto mais você matar, mais você fará morrer', ou 'quanto mais você deixar morrer, mais por isso mesmo, você viverá'. Eu diria que essa relação ('se você quer viver, é preciso que você faça morrer, é preciso você possa matar') afinal não foi o racismo, nem o Estado moderno que inventou. É a relação guerreira: 'para viver, é preciso que você massacre seus inimigos' (FOUCAULT, 2010, p. 304).

É por essa dupla função características desse novo racismo que Foucault constrói as bases para o que posteriormente poderá ser invocado como biopolítica, isto é, uma forma de fazer a política, uma arte política como governo ou controle de populações. Normalmente parece que o racismo tomado em sua acepção cotidiana parece indicar apenas para a segunda das funções, para a prática teórica da exclusão. No entanto, há uma teoria prática precedente a esse movimento, que é a de "Uma ordenação eugênica da sociedade, com o que ela podia comportar de extensão e intensificação dos micropoderes, a pretexto de uma estatização ilimitada, era acompanhada pela exaltação onírica de um sangue superior" (FOUCAULT, 2017, p. 139). Sem um levantamento prévio, um arranjo dos saberes de um determinado momento que legitimem as práticas racistas, a construção de características dessas raças como degeneração patológica do humano do lado da medicina, e a incidência de normas que diminuam a capacidade de agência (a identificação de sujeitos incapazes que precisam de tutela para realizar atos na vida civil) desses grupos, nada disso seria permitido. É só por meio de uma perspectiva violenta que implicava "ao mesmo tempo, o genocídio sistemático dos outros e o risco de expor a si mesmo a um sacrifício total. E a história quis que a política hitleriana do sexo tenha-se tornado uma prática irrisória (...)” (FOUCAULT, 2017, p. 139).

O racismo se forma nesse ponto (racismo em sua forma moderna, estatal, biologizante): toda uma política do povoamento, da família, do casamento, da educação, da hierarquização social, da propriedade, e uma longa série de intervenções permanentes ao nível do corpo, das condutas, da saúde, da vida quotidiana, receberam então cor e justificação em função da preocupação mítica de proteger a pureza do sangue e fazer triunfar a raça. Sem dúvida, o nazismo foi a combinação mais ingênua e mais ardilosa - ardilosa porque ingênua - dos fantasmas do sangue com os paroxismos de um poder disciplinar (FOUCAULT, 2017, p. 139). ${ }^{3}$

\footnotetext{
${ }^{3}$ A última indicação está na coletânea de textos escolhidos chamada Microfísica do poder. Nela não está mais presente o termo racismo tal qual foi produzido nos idos de 75 , mas o objeto de investigação da cidade e do corpo atravessados pelo biopoder e pela biopolítica é mais nítido: "Na medida em que a cidade se torna um importante lugar de mercado que unifica as relações comerciais, não simplesmente a nível de uma região, mas a nível da nação e mesmo internacional, a multiplicidade de jurisdição e de poder torna-se intolerável. A indústria nascente, o fato de que a cidade não é somente um lugar de mercado, mas um lugar de produção, faz com que se recorra a mecanismos de regulação homogêneos e coerentes" (FOUCAULT, 1982, p. 86).
} 
Percebe-se que algumas das considerações recolhidas que delineiam o que Foucault está chamando de "racismo de estado" contêm elementos problematizadores cruciais. O primeiro deles é a não referência explícita aos grupos, deslocando a sua identificação para aquilo que o conjunto de políticas públicas estatais vai chamar de raça. Por configurações outras que não o contexto brasileiro, a ligação do racismo com a questão dos negros não é direta, e tampouco há uma relação necessária entre os processos de escravização africana em território nacional que é uma das marcas das desigualdades e das discriminações na história do país. O mesmo caso acontece, do lado da Europa, com as complexas raízes de exclusão social do antissemitismo.

Michel Foucault procura, a partir das complexidades às quais se defrontou, retornar ao paradigma como modos de pensamentos científicos organicamente vinculados a estruturas de saber e de poder. Ou mesmo, vê-se que a noção de "racismo" aparece ligada diretamente ao biopoder, uma formatação social que tenta separar o social do resto por meio da política de incentivo ao extermínio desse mesmo resto. O racismo, portanto, localiza-se além das fronteiras sociais internas. Ele é acima de tudo um grande projeto, ou, contrariando muitos dos pensadores que defendem essa causa, ele é, segundo essa perspectiva crítica aberta por Foucault, o grande projeto da modernidade.

\section{DESDOBRAMENTOS DE UM PROBLEMA FOUCAULTIANO}

As fortes posições de Michel Foucault ajudam a pensar o papel do poder e do próprio Estado na configuração atual de nossas sociedades. Pensar a produção dos lugares, das posições sociais e até mesmo dos rejeitados. Em outras palavras, “o termo 'racismo' empregado por Foucault pode hoje, com relativa facilidade, abrigar as diferenças de raça e cor, de padrões midiaticamente exigidos, quer no corpo físico, quer no desempenho intelectual" (CANDIOTTO; SALOMÉ D’ESPÍNDULA, 2012, p. 33-34). Essas diferenças de raça e de cor promovem uma ampla zona de visibilidade a partir das quais será possível pensar alternativas que visam diminuir essas desigualdades por uma atuação mais ativa dos juristas para com o direito.

Dessa forma, nessa mesma discussão, há outros elementos que têm se somado à discussão da "desigualdade" seja ela pensada a partir de mecanismos do Estado ou no bojo das relações sociais, de maneira que 
Em síntese, os tempos de biopoder, que também são os nossos, caracterizamse pela ampliação crescente das articulações dos saberes biológicos e biomédicos com os dispositivos jurídico-institucionais, com grandes efeitos no campo da macropolítica, seja nas relações entre os Estados, seja no interior de cada Estado, indo até mesmo à interferência, micropolítica, no modo de vida das pessoas (CASTELO BRANCO, 2017, p. 31).

Isso faz que o debate primordial em torno da questão esteja focado em uma urgência para teorizar a categoria que parece ser o eixo sendo no qual todas as incidências parecem cair. Trata-se da categoria polêmica de sujeito. Para isso, segundo o campo de problemas que surgem a respeito do "racismo de estado", a rigor, parecem sempre procurar identificar um corpo individual e caracterizá-lo como sujeito dotado de certas identidades racistas, tendo como resultado sua autoclassificação para usufruir ou não das garantias e liberdades de um determinado espaço de liberdade estatal.

Neste debate, percebe-se que há ao menos três acepções básicas para se compreender como uma noção prévia da categoria de sujeito pode se relacionar com o modelo apresentado por Foucault: o sujeito visto como agente ativo dotado de agência em um espaço preestabelecido de liberdade, que pratica verbos e provoca circunstâncias; o sujeito como agente passivo, isto é, aquele que é assujeitado por regras determinadas ou prescrições que compõem, antes de sua ação, uma identidade prévia; o sujeito como tema genérico, como assunto que não atende aos pedidos nem da ação nem da recepção.

No primeiro caso, tem-se assim uma instância como potência de agir, uma ordem reguladora que a partir de sua própria ação, consegue estabelecer critérios morais e relacionais com outros agentes; ele impõe sua força como ação e é capaz de apreender quais são as que podem ser encaradas, ao mesmo tempo em que distingue aquilo que não tem força: os objetos. No segundo, tem-se a figura do súdito. Uma instância receptadora e reflexo das ordens injuntivas, é o sujeito assujeitado que se coloca a disposição de ação que não as dele e ainda as acolhe baixando a cabeça ao mesmo tempo em que afirma sua posição inferior. No terceiro caso, é possível visualizar o sujeito como temático.

Em que medida essa relação entre o sujeito e o "racismo de estado" é importante é uma das perguntas que ficaram ainda por serem respondidas. Após suas lições do ano de 76, Foucault não retorna a esse assunto diretamente, seus interesses se deslocam para os temas biopolíticos, mais a frente para o neoliberalismo, e finalmente para as questões envolvendo curiosamente as práticas para a construção dos sujeitos. É a partir desse recorte histórico que os 
pensadores do tempo seguinte irão se desdobrar para responder, cada qual a sua maneira, o enigma do "racismo de estado".

Como bifurcação, talvez os comentadores mais famosos sejam Giorgio Agamben e Achille Mbembe. Sempre tendo como referência as lições sobre o "racismo de estado", cada qual tenta propor algumas outras considerações para adequar o primeiro desenho conceitual feito por Foucault às novas realidades e fatos contemporâneos.

É preciso ir de encontro com as considerações tecidas por Giorgio Agamben a respeito de nossa capacidade de criarmos um sujeito autêntico contemporâneo que reverta as políticas racistas estatais, o filósofo italiano inclui, dentro dessa lógica, três questões interligadas: uma forma que produz essa dessubjetivação por meio de sua própria coerção que é chamada de campo (e como exemplo concreto, elenca o campo de concentração), como paradigma biopolítico do moderno; um Estado que produz os mesmos mecanismos acima é chamado de estado de exceção (como exemplo, não só os regimes totalitários do século XX como a postura de guerra assumida por alguns dos países ocidentais como os Estados Unidos), como paradigma de governo; um sujeito descaracterizado que representa o próprio vazio das relações, bloqueado das experiências e, em certos casos, até da própria linguagem, um receptáculo de normalizações, um objeto de experiências, o paradigma aqui é vida nua, e seu personagem representativo é o antigo instituto do direito romano, o homo sacer (AGAMBEN, 2008, p. 5253).

Uma figura enigmática do direito romano arcaico, que parece reunir em si traços contraditórios e por isso precisava ela mesma ser explicada, entre assim em ressonância com a categoria religiosa do sagrado no momento em que esta atravessa por conta própria um processo de irrevogável dessemantização que a leva a assumir significados opostos; esta ambivalência, posta em relação com a noção etnográfica de tabu, é usada por sua vez para explicar, com perfeita circularidade, a figura do homo sacer (AGAMBEN, 2010, p. 82).

Vê-se que essa mera vida ou vida nua se aproxima muito do conceito de sujeito, na medida em que o "racismo do estado" também tende a se confundir com o estado de exceção. Sem aprofundar os detalhes do projeto de sua obra, o importante é perceber como essas descrições feitas por Agamben têm em uma das suas origens a influência do pensamento de Foucault. Como uma metodologia e marcos teóricos bastante distintos, o italiano ainda preserva a estrutura dada e antecipada por Foucault.

Tomada por uma outra perspectiva, o "racismo de estado", na acepção construída por Achille Mbembe assume caracteres mais diretos com os processos de racialização ligados a 
processos de dominação e racionalização do mundo. Tomada como uma forma de relação social (jurídica e política), a racialização é um projeto que caminha ao lado do processo de racionalização do Ocidente, tendo um ponto de origem e um desenvolvimento históricos respectivamente quanto a si mesmos.

É por essa razão que Mbembe vê as politicas públicas estatais segregadoras como uma necropolítica. Em Políticas da Inimizade, ele conclui seu capítulo sobre seu conceito afirmando:

Neste capítulo discutimos as formas contemporâneas de subjugação da vida ao poder da morte (necropolítica) que reconfiguram profundamente as relações entre resistência, sacrifício e terror. Demonstramos que a noção de biopoder é insuficiente como resposta às formas contemporâneas de subjugação da vida ao poder da morte. Mais adiante, propomos a noção de necropolítica e de necropoder como descrição dos vários modos existentes, no nosso mundo contemporâneo, de distribuição de armas, com o objetivo da máxima destruição de pessoas e da criação de mundos-de-morte, modos novos único de existência social, nos quais vastas populações estão sujeitas a condições de vida muito próximas do estatuto de mortos-vivos. O presente capítulo chama ainda a atenção para as topografias da crueldade reprimidas (as plantações e as colônias, em particular) e sugere que, sob as condições do necropoder, as linhas entre resistências e suicídio, sacrifício e redenção, martírio e liberdade, são difusas (MBEMBE, 2017, p. 151-152).

Também parcialmente desvinculado na assunção de que os processos racistas estão ligados com a cor da pele, Mbembe parece sugerir que as políticas de qualquer estado que percebe seus participantes como pertencentes de "raças" diferentes é já um estado aplicador de uma política racista. Era assim que as plantation das colônias tropicais funcionavam.

Essa chave de leitura permite Mbembe ainda renovar outro ponto que Foucault deixou, qual seja, os processos mesmos de exclusão. Diante de sua análise das situações, Mbembe defende que a racialização, isto é, o processo de construir e fixar uma identidade racial em um grupo ou em um corpo é um processo histórico que se faz por aqueles que se beneficiam desse dispêndio social. Assim, quanto mais os dominantes se destacam dos dominados, mais racializados eles são. O todo social contemporâneo, que é dominado economicamente por um número muito pequeno de humanos, procura, portanto, racializar todo o espaço global, fazendo que um devir-negro do mundo apareça. É nesses mundos-de-morte, em suas palavras, que se desenha como o horizonte do futuro para todos aquelas minorias racializadas que compõem numericamente uma grande massa de sujeitos (ou quase-sujeitos, mortos-vivos, segundo Mbembe). 
Para que haja um direito que se proponha a ser o menos racista possível, um instrumento dessa reversibilidade no plano estatal, é preciso antes identificar e afirmar o caráter eminentemente segregador dos Estados, em uma conjuntura que tome uma posição crítica a respeito da real situação. O trabalho de Michelle Alexander provou que no país de maior população carcerária, o fenômeno do encarceramento em massa passa exatamente pelos crivos apontados na seção anterior do "racismo de estado" (ALEXANDER, 2010, p. 4). A exclusão possui uma imanência latente que não se fragiliza simplesmente com a implementação de proposta de redução de danos ou até mesmo com mudanças aparentes no sistema social, é preciso buscar as raízes.

\section{AINDA SOBRE RAÇA E RACISMO}

Muito embora o acesso a direitos tenha sido comumente pensado em termos de garantias individuais e coletivas, destinadas indiscriminadamente a uma totalidade de cidadãos, a discussão proposta neste ensaio pretende apontar para outras direções, entre as quais a relação que se estabelece entre raça, racismo, estado e acesso a direitos e oportunidades, como uma tentativa de compreensão da maneira pela qual a raça e o racismo - compreendidos sistemicamente - agem no acesso a direitos e no acesso a oportunidades constitutivas da vida em sociedade.

Como mencionamos acima, neste ensaio, propusemos compreender a ideia de raça de maneira dissociada de categorizações que a aproximem de traços meramente biológicos. Pretendemos tomar a noção de raça como elemento construído tanto discursivamente quanto socialmente e, ao fazê-lo, analisar as implicações ou melhor a relevância da raça - construída histórica e socialmente - no Direito. Dessa forma, compreende-se que "a raça é uma construção social que tem a função particular de organizar as formas de operação da sociedade". (MOREIRA, 2017, p. 151).

Se compreendemos a raça como uma construção social, torna-se necessário compreender também como essa noção construída socialmente age diretamente na vida das pessoas tanto para inclui-las em relações sociais quanto para determinar lugares de pertencimento caracterizados como verdadeiros processos de exclusão.

Dessa forma, longe de ser questão meramente lexical ou semântica, raça, racismo, exclusão e estado são lexias que, embora marquem lugares distintos de compreensão, estão 
relacionadas por construções sociais e históricas que contribuem para o posicionamento de determinados grupos em lugares subalternos, destacando como a exclusão pode ser realizada por meio da reprodução de modelos estruturais de exploração centrados na raça. Assim,

fenômenos como o racismo [...] não são apenas práticas discriminatórias. Eles são verdadeiros sistemas de dominação social porque influenciam diferentes aspectos da vida dos indivíduos. Eles também determinam como atores públicos e privados tratam grupos minoritários, além de reproduzirem o ideário social que legitima a subordinação deles. Assim, esses sistemas de subordinação social são responsáveis pela criação de desigualdade de status cultural e também de desigualdade de status material, a primeira diz respeito ao preço que os grupos possuem dentro da sociedade, a segunda às condições materiais de existência. (MOREIRA, 2017, p. 33).

O caráter sistêmico do racismo, ao apontar para processos de dominação social também apontam para usos da raça e do próprio racismo como ferramentas de um processo de estratificação social perpetrado pela raça e de dominação social, que se fortalecem por meio de práticas e ações que insistem em posicionar indivíduos de grupos minoritários em lugares subalternos. Dessa forma,

as interações humanas estão envoltas em relações de poder. Além de legitimarem arranjos sociais que permitem o acesso à criação e preservação de vantagens materiais para os membros dos grupos majoritários, elas também permitem que eles possam criar sentidos culturais. (...) as distinções entre grupos sociais não são produtos de diferenças naturais entre eles. Elas são socialmente construídas em função do poder que um grupo tem de universalizar sentidos culturais. Por esse motivo, negros e brancos, homens e mulheres, heterossexuais e homossexuais não designam meras diferenças biológicas, mas diferentes formas de pertencimento social decorrentes do status de subordinação no qual vivem. (MOREIRA, 2017, p. 34).

São essas formas de pertencimento social, legitimadas por práticas excludentes que afastam a classificação de grupos minoritários - como os negros, os homossexuais e as mulheres - apenas por diferenças biológicas. A classificação à qual integrantes de grupos minoritários estão sujeitos passa por prática de construção social que reiteradas são tornadas sistêmicas e estruturais. Concebidos socialmente, dessa maneira, esses grupos são posicionados em lugares inferiores àquele ocupado por grupos majoritariamente dominantes. Agindo como uma estrutura muito bem definida que determina o lugar que cada indivíduo deve ocupar, a classificação baseada na raça, no racismo e em outras práticas excludentes de grupos minoritários marca, fortalece e mantém grupos inteiros de indivíduos em uma condição de subalternidade. É por isso que 
A intenção de discriminar alguém está frequentemente baseada no interesse na preservação de arranjos sociais que mantêm certos grupos em uma situação de privilégio em outros em uma condição subordinada. Os procedimentos utilizados para isso são legitimados por uma série de estereótipos culturais, representações criadas por grupos majoritários, segmentos que têm o poder simbólico e político para construir e difundir sentidos culturais. (MOREIRA, 2017, p. 29)

Como é possível notar, processos discriminatórios (negativos) podem estar associados a mais de uma finalidade. Esses processos e essas ações não se relacionam apenas com a marcação da diferença ou com a definição de uma posição subalterna de determinados grupos em relação a outros. Processos discriminatórios agem também na manutenção e na perpetuação desses lugares de pertencimento social. Ou seja, processos discriminatórios também são acompanhados de outros interesses que apontam para a manutenção de uma estrutura social que posiciona grupos de indivíduos em posições majoritariamente favoráveis em detrimento do posicionamento de grupos minoritários em posições subalternas, como dissemos acima, de forma que "a discriminação tem um papel central em um processo social mais complexo que é a estratificação social: a persistência de práticas discriminatórias ao longo do tempo faz com que certos grupos sociais sejam transformados em sujeitos subalternos" (MOREIRA, 2017, p. 195).

Nessa mesma direção, apesar de conceitos como raça e racismo serem distintos semanticamente, tem sido possível observar que discussões relacionadas à ideia de racismo comumente têm tido espaço quando se discute o acesso a direitos por grupos minoritários posicionados subalternamente em lugares sociais distintos de grupos majoritários. Esse é o caso, por exemplo de abordagens que saem em defesa da política de cotas de acesso ao serviço público e ao ensino superior, mas também de abordagens que rechaçam a possibilidade de um determinado grupo de pessoas receber tratamento mais benéfico que outro.

Notadamente, é comum chamar em causa argumentos que se relacionam com a efetividade de uma igualdade formal que dispensaria a necessidade de que grupos de indivíduos recebam tratamento diverso que outros grupos. São abordagens como essa que fortalecem a necessidade de compreensão da relevância da raça e do racismo no direito e que apontam para a ideia de raça como uma categoria central tanto para pensar o próprio "racismo de estado" quanto para a compreensão da maneira pela qual processos de "igualdade" são construídos, sobretudo quando "a raça impede o acesso das pessoas a oportunidades necessárias para uma vida digna". (MOREIRA, 2019, p. 21). 
Um dos principais problemas de abordagens que propõem a adoção de um modelo de tratamento centrado nos parâmetros de uma igualdade formal é a desconsideração do uso de práticas, ações e ferramentas que concorrem diretamente para o funcionamento e para a manutenção de uma estrutura que insiste em definir posições sociais e culturais por meio das noções de raça e racismo, já que "atos discriminatórios não acontecem dentro de um vácuo social, eles procuram afirmar a suposta inferioridade de um grupo e também manter o status privilegiado de membros dos segmentos majoritários”. (MOREIRA, 2019, p. 31).

Nesse ponto, o que se destaca é a impossibilidade de se advogar pelos mesmos acessos e pelos mesmos tratamentos, quando os mesmos indivíduos estão socialmente posicionados em lugares distintos. Seria o mesmo que admitir que um grupo de pessoas disputasse uma corrida, com as mesmas regras, mas, com corredores largando em posições distintas na pista de corrida, de forma que "a discriminação estrutural ocorre quando a acumulação de desvantagens sociais causadas por diversas formas de discriminação concorre para a estratificação, o que coloca certos grupos em uma situação de subordinação durável ou permanente”. (MOREIRA, 2017, p. 136).

É dessa maneira que tem sido apontado que processos discriminatórios possuem uma racionalidade específica, própria do interesse em manter grupos posicionados em lugares subalternos.

A intenção de discriminar alguém está frequentemente baseada no interesse na
preservação de arranjos sociais que mantêm certos grupos em uma situação de
privilégio em outros em uma condição subordinada. Os procedimentos
utilizados para isso são legitimados por uma série de estereótipos culturais,
representações criadas por grupos majoritários, segmentos que têm o poder
simbólico e político para construir e difundir sentidos culturais. (MOREIRA,
2017, p. 29)

Nesse sentido, para o jurista Adilson José Moreira (2017; 2019) é necessário pensar os processos de exclusão construídos por meio da categoria raça para além de mecanismos diretos de discriminação. Processos de exclusão não ocorrem apenas por meio do que o jurista classifica como ações intencionais ou arbitrárias. A exclusão, compreendida como processo estrutural, precisa ser lida e compreendida também a partir do que não é dito, do que não é escrito, ou seja, do que não é direto.

Essas práticas também são fundamentadas e fortalecidas em mecanismos silenciosos, silenciados, mas que revelam verdadeiro modus operandi de processos estruturais de exclusão, de forma que "os processos de estratificação racial presentes na nossa nação não trazem apenas 
desigualdades materiais, eles provocam uma hierarquia de valor entre os membros de diferentes grupos raciais". (MOREIRA, 2019, p. 35).

Ações como as descritas pelo jurista apontam para processos nos quais indivíduos que pertencem a determinados grupos são "desconstituídos" tanto pelo lugar que ocupam na estrutura social quanto pelo acesso a direitos e a outros elementos constitutivos da vida em sociedade. Muito embora as ações também sejam simbólicas, não são apenas simbólicas, de forma que "a desumanização racista, não é apenas simbólica; ela delimita as fronteiras do saber" (MORRISON, 2019, p. 16).

As situações de práticas estruturais de exclusão de indivíduos que pertencem a determinados grupos - sejam essas práticas invisíveis ao direito ou materializadas em processos estruturais de exclusão - além de revelarem tratamento desvantajoso por parte de grupos de indivíduos que não têm acesso às mesmas condições tampouco aos mesmos direitos que grupos majoritários também revelam, ou ao menos apontam, que do ponto de vista do Estado e de Políticas Públicas, muitos desses indivíduos sequer chegam a ser contemplados. Esse é o caso, por exemplo do reconhecimento das uniões homoafetivas, que apenas recentemente teve espaço no ordenamento jurídico brasileiro.

Essa desvantagem ou esse tratamento desvantajoso - tanto objetivo quanto silencioso sofrido por indivíduos de alguns grupos reforça novamente a compreensão que "a exclusão social não decorre necessariamente de atos materiais de discriminação, sejam eles diretos ou indiretos. Ela pode acontecer em função de uma dimensão da discriminação que permanece socialmente invisível." (MOREIRA, 2017, p. 145). Essa exclusão destaca que a raça enquanto categoria construída socialmente é relevante no acesso a direitos, a políticas públicas e ao posicionamento de grupos de indivíduos na sociedade, um posicionamento marcado por práticas sistêmicas e discriminatórias que evidenciam as relações de poder que constituem a vida em sociedade, reforçando a noção que "sujeitos sociais estão imersos em diversas relações assimétricas de poder, sendo que elas sempre se entrecruzam, o que os torna vulneráveis de diversas maneiras (MOREIRA, 2017, p. 109).

A compreensão de que práticas excludentes construídas e materializadas por meio das noções de raça e racismo, podem agir tanto de maneira objetiva, ou seja, por meio de ações concretas de exclusão como por ações indiretas, silenciosas, invisibilizadas que quase naturalizadas reforçam a ideia de estrutura, de práticas sistêmicas, ou seja, de um engendramento social que insiste em posicionar indivíduos de determinados grupos em 
posições inferiores, subalternas quando relacionados a grupos majoritariamente superiores. Essa relação dicotômica também pode ser evidenciada quando se rejeita a ideia de uma sociedade fundamentada e estratificada na noção de raça e de racismo, mas a vida de indivíduos de determinados grupos, aponta para outra direção, destacando a existência de "uma cultura social que condena o racismo, mas que matem um sistema de exclusão que atua independentemente da vontade individual” (MOREIRA, 2017, p. 138).

Finalmente, é importante ter em mente que "o racismo faz diferença. Ser um outro neste país faz diferença, e a verdade desanimadora é que provavelmente continuará a fazer. É raro que comunidades humanas abram mão de privilégios por simples altruísmo”. (MORRISON, 2019, p. 17).

\section{CONCLUSÃO}

Como conclusão, a partir do que foi apresentado no que tange aos problemas do racismo e da exclusão, a impressão que se tem é que se trata de uma tentativa que ainda está longe de ser levada a cabo por todas as suas vertentes. Sem qualquer pretensão de esgotar mesmo os assuntos apresentados, o que foi procurado deixar em evidencia é justamente a complexidade da temática, por um lado, pelas considerações e deduções possíveis de se fazer do conceito "racismo de estado" de Foucault e seus desdobramentos em Agamben e Mbembe, e por outro, apresentar como a experiência da discriminação e da exclusão impedem a participação plena na vida em sociedade, pelo jurista Moreira e pela crítica literária Morrison.

O engajamento essencial foi de mostrar que a exclusão social configura-se como um problema social fundante, uma moldura dentro da qual somente é possível pensar a vida em sociedade contrariando as teses harmoniosas do contrato social coletivo ou da finalidade social como bem comum. É preciso estar ciente de que toda forma de exclusão é uma forma de associação, e que essa lógica percorre séculos e séculos de reprodução. Dentro desse esquema, o papel do direito e dos juristas é fundamental, pois há um papel decisivo que deve ser cumprido ou pelo lado conservador da reprodução das exclusões, ou pelo lado transformativo de não querer permanecer as mesmas formas de dominação promovidas pelo complexo jurídico.

Se se trata de uma jurisdição da sociedade, ou da exclusão social, o ativador desse gerenciamento dos excluídos carrega o nome conceitual de racismo. E, de forma alargada, 
pode-se nomeá-lo de "racismo de estado". Dessa forma, ambos são, de algum modo, nutridos por atividades totalitárias e segregativas. Diante dessa realidade, pode-se deduzir o comprometimento crítico do primeiro grupo de apresentação que busca pensar conceitualmente tais dinâmicas. Pode-se ainda ressalvar alguns problemas ou desafios principais do problema colocado na forma geral de apontamentos e reflexões, por tratar-se, como anunciado, de um estudo incipiente cujas questões centrais pretende-se desenvolver e explorar em trabalhos posteriores.

É dessa forma que o debate sobre a maneira pela qual relações sociais são construídas, a partir de um debate que visa também pensar o acesso a direitos - dentro de um sistema constitucional de garantias de direitos - ao conceber práticas fundamentadas em processos objetivos, mas também em processos indiretos de classificação de sujeitos pode apontar para verdadeiras estruturas de posicionamento social inferior de indivíduos, ações fundamentadas no que contemporaneamente tem sido categorizado como racismo e raça do ponto de vista de uma construção social. Essa discussão, associa-se ao que mencionamos acima a partir do conceito de raça como núcleo de uma política pública estatal de longa data, que evidencia que a exclusão social pode se dar por meio da exploração e reprodução no campo das raças.

Por fim, cabe a cada um assumir uma posição dentro dessa fragmentação contemporânea. Sem dúvida, talvez estejamos pela primeira vez sofrendo uma mudança estrutural dentro da sociedade, e a convulsão e ebulição podem estar revelando elementos para uma possível superação. Isso quer dizer nada mais que lutar contra o racismo, pelo direito ou contra o direito, é uma ação urgente.

\section{REFERÊNCIAS}

AGAMBEN, Giorgio. Homo Sacer: o poder soberano e a vida nua I. tradução de Henrique Burigo. 2. ed. Belo Horizonte: Editora UFMG, 2010.

AGAMBEN, Giorgio. O que resta de Auschwitz: o arquivo e a testemunha (Homo Sacer III). Tradução Selvino J. Assmann. São Paulo: Boitempo, 2008.

ALEXANDER, Michelle. The New Jim Crow: Mass Incarceration in the Age of Colorblindness. New York \& London: The New Press, 2010.

CANDIOTTO, Cesar; SALOMÉ D’ESPÍNDULA, Thereza. Biopoder e Racismo Político: Uma análise a partir de Michel Foucault. Revista Internacional Interdisciplinar INTERthesis, Florianópolis, v. 9, n. 2, p. 20-38, dez. 2012. ISSN 1807-1384. Disponível em: 
<https://periodicos.ufsc.br/index.php/interthesis/article/view/27325>. Acesso em: 28 nov. 2017. doi:http://dx.doi.org/10.5007/1807-1384.2012v9n2p20.

CASTELO BRANCO, Guilherme. RACISMO, INDIVIDUALISMO, BIOPODER. Revista de Filosofia Aurora, [S.1.], v. 21, n. 28, p. 29-38, maio 2017. ISSN 1980-5934. Disponível em: <https://periodicos.pucpr.br/index.php/aurora/article/view/1132〉. Acesso em: 28 nov. 2017.

FOUCAULT, Michel. A sociedade punitiva: curso no Collège de France (1972-1973). Trad. Ivone C. Benedetti. São Paulo: Editora WMF Martins Fontes, 2015.

FOUCAULT, Michel. Doença mental e psicologia. Trad. Lilian Rose Shalders. 6. ed. Rio de Janeiro: Tempo Brasileiro, 2000.

FOUCAULT, M. Microfísica do Poder. Organização e introdução de Roberto Machado. 3.ed. Rio de Janeiro: Graal, 1982.

FOUCAULT, Michel. Em defesa da sociedade: curso no Collège de France (1975-1976); tradução Maria Ermantina Galvão. - 2ª . Ed. São Paulo: Editora WMF Martins Fontes, 2010.

FOUCAULT, Michel. História da sexualidade 1: A vontade de saber. Tradução de Maria Thereza da Costa Albuquerquer e J. A. Guilhon Albuquerque. $-4^{\text {a }}$ ed. - Rio de Janeiro/ São Paulo, Paz e Terra, 2017.

FOUCAULT, Michel. Vigiar e punir: nascimento da prisão; tradução de Raquel Ramalhete. 42. ed. Petrópolis, RJ: Vozes, 2014.

MBEMBE, Achille. Políticas da inimizade. Trad. Marta Lança. Lisboa: Antígona, 2017.

MOREIRA, Adilson José. O que é discriminação? Belo Horizonte: Letramento; Casa do Direito; Justificando, 2017.

MOREIRA, Adilson José. Pensando como um negro: ensaio de hermenêutica jurídica. São Paulo: Contracorrente, 2019.

MORRISON, Toni. A origem dos outros. Tradução Fernanda de Abreu. Prefácio Ta-Nehisi Coates. São Paulo: Companhia das Letras, 2019. 